\title{
Prevalence of Myopia and its Risk Factors in Rural Schoolchildren
}

\author{
${ }^{1}$ Praveena Kher, ${ }^{2}$ Pavitra K Patel
}

\begin{abstract}
Introduction: Myopia, also known as short sightedness, is a type of refractive error in which parallel rays coming from infinity are focused in front of the retina when accommodation is at rest. It is a condition in which close objects are seen clearly, but objects farther away appear blurred. It is an ophthalmic condition affecting $30 \%$ population. It is commonly seen in schoolchildren aged 8 to 12 years. This study was undertaken to find the prevalence of myopia among students aged 5 to 16 years of a school in a rural area of Wardha, Maharashtra, India.
\end{abstract}

Materials and methods: Study sample included children between 5 and 16 years of age from a nearby rural school. We recorded degree of myopia by autorefractometer, and students with refractive error of $<-0.5 \mathrm{D}$ for at least one eye were considered as myopic. Strict inclusion and exclusion criteria were followed.

Results: It was found that the prevalence of myopia is $39.6 \%$. Mild to moderate degree of myopia was more common than severe one. Among the 198 myopic students, 112 were females and 86 were males. We found that there was no significant correlation between family history and presence of myopia. But, unhealthy reading habits and playing games on computer for 1 to 2 hours have an influence in the development of myopia.

Conclusion: Due to high magnitude of uncorrected myopia, it appears to be a public health problem both in urban and rural areas, which suggest that an increase in outdoor activity may help to reduce the magnitude of the problem. Schoolteachers should be involved for positive reinforcement of schoolchildren for screening.

Keywords: Cross-sectional, Myopia, Prevalence, Risk factors, Rural school.

How to cite this article: Kher P, Patel PK. Prevalence of Myopia and its Risk Factors in Rural Schoolchildren. Int J Recent Surg Med Sci 2017;3(1):29-33.

\section{Source of support: Nil}

Conflict of interest: None

\section{INTRODUCTION}

Myopia is a very common cause of visual impairment throughout the world. ${ }^{1,2}$ Though the prevalence of myopia varies by country, age, and ethnic group, it is a major

\footnotetext{
${ }^{1}$ Professor, ${ }^{2}$ Postgraduate Student

1,2Department of Ophthalmology, Datta Meghe Institute of Medical Sciences, Wardha, Maharashtra, India

Corresponding Author: Praveena Kher, Professor, Department of Ophthalmology, Datta Meghe Institute of Medical Sciences Wardha, Maharashtra, India, Phone: +919890845754, e-mail: praveenakher@yahoo.com
}

cause of visual impairment in both the developed and the developing world. ${ }^{2-4}$ While there are no large-scale studies in India for assessing the magnitude of myopia in the school-going population, the available studies show higher prevalence rates in urban areas compared with rural areas. ${ }^{5-7}$

Myopia is the state of refraction in which parallel rays of light are brought to focus in front of the retina of a resting eye. ${ }^{8}$ Myopia is measured by the spherical power in diopters of the diverging lens needed to focus light onto the retina, which can be expressed as the spherical equivalent or refraction in the least myopic meridian., ${ }^{9,10}$ The clinical correlates of myopia include blurred distance vision, eye rubbing, and squinting.

Myopia has been classified as either physiologic or pathologic. Physiologic myopia occurs due to an increase in the axial diameter of the eye over that which is attained by normal growth. It occurs as a result of correlative failure of the refractive components of the normal eye. Pathologic myopia is caused by an abnormal lengthening of the eyeball, and is often associated with thinning of the scleral wall. ${ }^{8}$

Severe myopia may be associated with myopic macular degeneration, cataract, glaucoma, peripheral retinal changes (such as lattice degeneration), and retinal holes and tears, as well as retinal detachment. Methods of correction of myopia are not without complications, including corneal infections due to contact lens wear and corneal scarring and persistent corneal haze from refractive surgery. ${ }^{11}$

There is an increased incidence of myopia among students. School myopia occurs at approximately 7 to 17 years of age and stabilizes by the late teens or early 20s. Both school and adult-onset myopia are mainly the result of idiopathic causes, while congenital myopia is often associated with other abnormalities. Alteration in visual power is common in the age group of 10 to 12 years. Students are found to be associated with lots of near work and prolonged accommodation. So, we were keen to observe risk factors that increase the incidence of myopia in this age group.

As there is no well-established or universally accepted method for the prevention of myopia onset, it is important to identify modifiable risk factors associated with its development and create cost-effective interventional 
strategies. This study was undertaken with the aim to assess the prevalence of myopia in school-going children in rural area and study the influence of environmental and hereditary factors and indoor activities like reading, watching television, and playing computer games in the development of myopia.

\section{MATERIALS AND METHODS}

The study was conducted in a rural hospital of Wardha, India, from July to December 2015. It was a randomized, cross-sectional study. Children in the age group of 5 to 16 years were selected from a rural school. Children with defective vision due to other reasons like refractive errors other than myopia, media opacities, retinal diseases, and history of ocular trauma/ocular surgery were excluded. Visual acuity was tested by Snellen's chart and refractive error by Topcon autorefractometer. Students with refractive error of $<0.5 \mathrm{D}$ for at least one eye were considered as myopic.

\section{Sampling Technique}

Each of the division was considered as one strata and simple random sample of clusters was selected from each standard. Thus, we took students from 1st to 12th standard. Each standard consists of three divisions, each with 41 to 45 students. A division was selected at random from all the classes. All the students of the selected division were selected to sample. Thus, a total of 500 students from that school were taken for the study. Visual acuity was tested using Snellen's chart. All students were interviewed by using self-administered questionnaire. Students were placed $6 \mathrm{~m}$ from Snellen's chart and asked to read the chart. Each eye was tested separately. From the findings, students were grouped as myopic and nonmyopic. This is to correlate the habits and their myopic stage.

\section{Ethical Clearance}

Ethical clearance was taken from the Institutional Ethical Committee.

\section{Statistical Analysis}

Data were entered in Microsoft Excel spreadsheet after ensuring completeness of the filled forms. Analysis was done using the Statistical Package for the Social Sciences (version 17.0) software by chi-square test. A p-value $<0.05$ was considered statistically significant.

\section{RESULTS}

It was found that the prevalence of myopia is $39.6 \%$ (Table 1 ). Mild to moderate degree of myopia was more common than severe one (Graph 1).
Table 1: Prevalence of myopia among study population $(n=500)$

\begin{tabular}{lll}
\hline Type of refractive error & Total $(n=500)$ & Percentage \\
\hline Myopia & 198 & 39.6 \\
No myopia & 302 & 60.4 \\
\hline Total & 500 & 100 \\
\hline
\end{tabular}

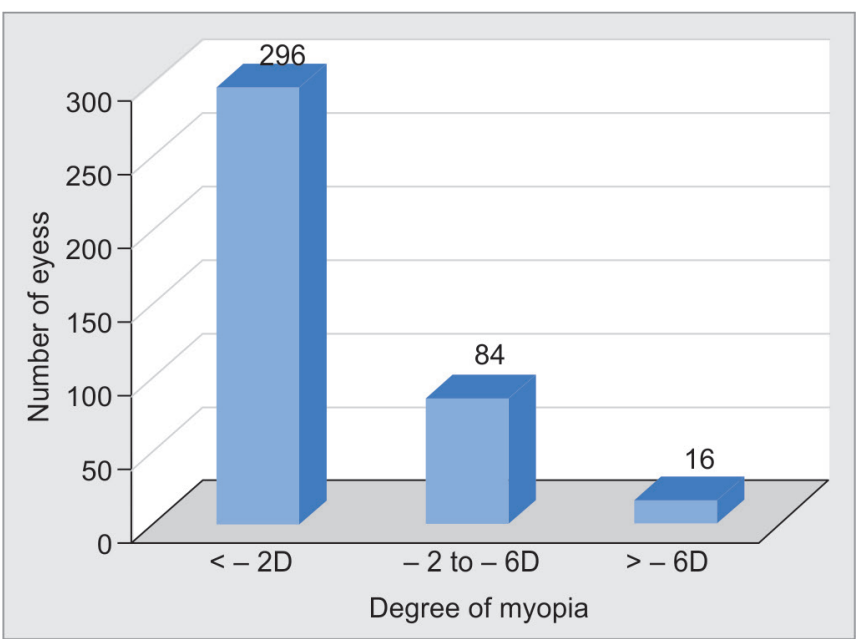

Graph 1: Distribution of degree of myopia

According to our study, the significant risk factors were:

- Reading books at a distance $>30 \mathrm{~cm}$.

- Continuous reading for 2 to 4 hours.

- Lower levels of outdoor activities.

In a study of 500 students, we found that 198 students were myopic. Among the 198 myopic students, 112 were females and 86 were males (Graph 2). We found that only 56 students were using spectacles. The rest did not use spectacles and had not approached the eye clinic before. A total of 142 students had undiagnosed myopia. The cause of this hidden group was due to lack of awareness or due to poor parental education and lack of proper care and attention given to the children and may be due to lack of health care facilities in the community.

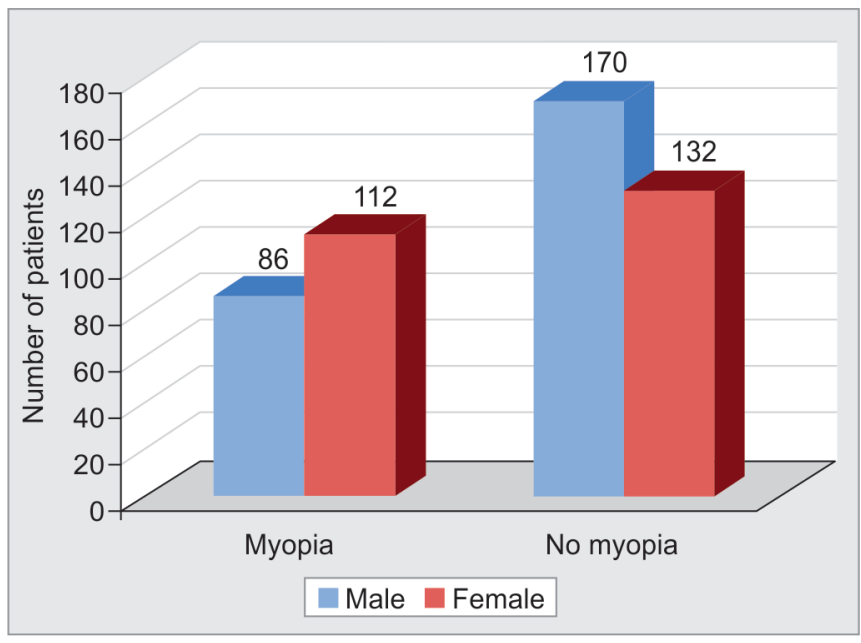

Graph 2: Gender distribution of myopia 
Prevalence of Myopia and its Risk Factors in Rural Schoolchildren

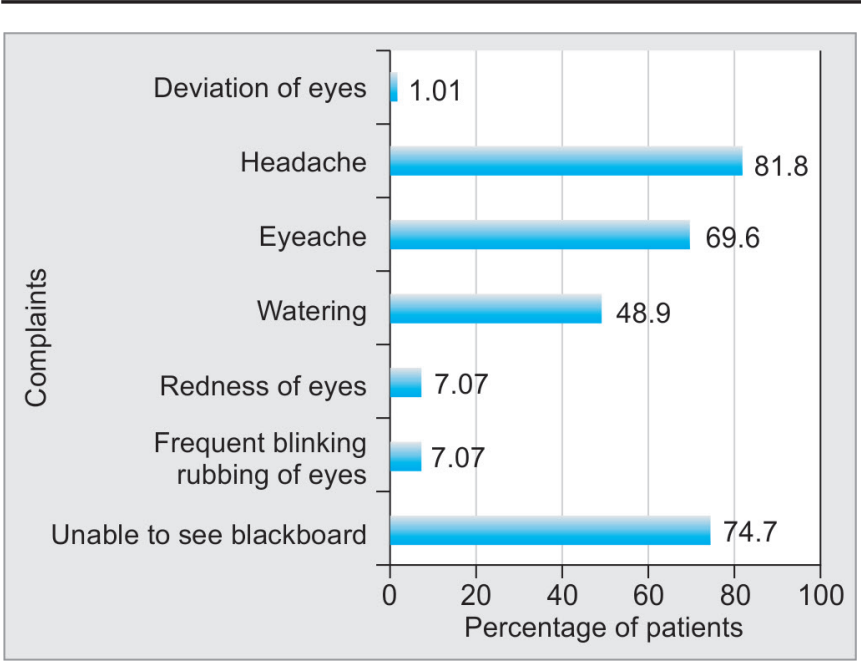

Graph 3: Clinical profile of myopic children

The teachers can detect most of the cases of myopia in children in the school if they give proper attention and care. A properly illuminated and ventilated class is a necessity, and the school environment should be such that it helps in proper development of health of the child. Proper awareness guidelines and medical camps should be conducted in school on myopia, so as to prevent and also detect new cases of myopia (Graph 3).

After the interview, students were found to have many risk factors, which contribute to the development of myopia as well as many factors, which prevent the incidence. In our study, we found that girls were more myopic than boys. But, we found that the relation between myopia and family history had no significance (Table 2). Indoor activities like watching TV or looking at computer at a near distance of $<30 \mathrm{~cm}$ may cause eye strain and reduced blinking rate, signs of which include blurred vision and red or watery eyes. Some students get headache from spending excessive time in front of TV or computer. To avoid some of these problems, it is advisable not to watch TV in a dark room, to sit a little further from the TV, to angle the computer screen straight ahead, and to use antiglare screen. Very close viewing of TV or computer screen may slightly increase the temperature of eye tissue due to electromagnetic radiation from screen (Tables 3 and 4).

Playing mobile games for a long time induces greater stress on the eye as mobile screen is so small and greater

Table 2: Frequency of myopia with family history

\begin{tabular}{llll}
\hline $\begin{array}{l}\text { Family member wearing } \\
\text { spectacles }\end{array}$ & Myopia & No myopia & p-value \\
\hline Father & 25 & 20 & 0.672 \\
Mother & 20 & 7 & \\
Both parents & 39 & 20 & \\
Siblings & 12 & 12 & \\
None & 141 & 263 & \\
\hline
\end{tabular}

Table 3: Relationship between myopia and television watching

\begin{tabular}{cllll}
\hline $\begin{array}{l}\text { Watching TV } \\
\text { distance }\end{array}$ & Total (\%) & Myopia & No myopia & p-value \\
\hline$<30 \mathrm{~cm}$ & $122(24.4 \%)$ & 78 & 44 & 0.053 \\
$>30 \mathrm{~cm}$ & $378(75.6 \%)$ & 120 & 258 & \\
\hline
\end{tabular}

Table 4: Relationship between myopia and computer use

\begin{tabular}{lllll}
\hline $\begin{array}{l}\text { Computer } \\
\text { duration (hours) }\end{array}$ & Total (\%) & Myopia & No myopia & p-value \\
\hline NA & $345(69 \%)$ & 125 & 220 & $0.04^{*}$ \\
$<1$ hour & $96(19.2 \%)$ & 28 & 68 & \\
$1-2$ hours & $36(7.2 \%)$ & 24 & 12 & \\
$>2$ hours & $23(4.6 \%)$ & 21 & 2 & \\
\hline
\end{tabular}

NA: Not applicable

stress is needed to play the game. Many parents are not aware of these side effects and so let their children to play with these for a longer period of time.

Unhealthy reading habits have an influence in the development of myopia (Tables 5 and 6). This was also proved by our study. Reading in supine position increases the chance of being myopic. Multiple reading style increases the stress on eye muscles. To overcome the stress, they tend to read at a close distance. A child who habitually reads while lying on left side will probably develop more myopia in left side than in right eye because the left eye is more closer to the book and vice versa. The importance of good lighting is that it causes the pupil to constrict, requiring less accommodation. Parents are not properly aware of possible problems that can occur due to unhealthy reading habits. It may possibly be due to illiteracy and lack of health professionals to properly guide them. Students who spent more time for outdoor activities have less chances of development of myopia as they spent less time for near work.

\section{DISCUSSION}

From our study, it was found that the prevalence of myopia among the rural schoolchildren was $39.6 \%$. Our

Table 5: Frequency of myopia with reading duration

\begin{tabular}{cllll}
\hline $\begin{array}{l}\text { Time spent for } \\
\text { reading in a } \\
\text { day (hours) }\end{array}$ & Total (\%) & Myopia & No myopia & $p$-value \\
\hline$<2$ hours & $344(68.8 \%)$ & 120 & 224 & $0.03^{*}$ \\
$2-4$ hours & $118(23.6 \%)$ & 58 & 60 & \\
$>4$ hours & $38(7.6 \%)$ & 20 & 18 & \\
\hline
\end{tabular}

Table 6: Relationship between myopia and reading distance

\begin{tabular}{cllll}
\hline $\begin{array}{c}\text { Reading } \\
\text { distance }\end{array}$ & Total (\%) & Myopia & No myopia & $p$-value \\
\hline$<30 \mathrm{~cm}$ & $334(66.8 \%)$ & 44 & 290 & $0.02^{*}$ \\
$>30 \mathrm{~cm}$ & $166(33.2 \%)$ & 154 & 12 & \\
\hline
\end{tabular}


study found relationship between environmental factors and indoor activities (watching TV, computer, reading duration, etc.) and low levels of outdoor activities and unhealthy reading habits with myopia.

It was found that prevalence of myopia was $8.6 \%$ among schoolchildren in South India. In another study, it was found that the prevalence of myopia increased from $34 \%$ in 2000 to $59 \%$ in 2005 . The increased prevalence of myopia is associated with increasing educational pressure along with life changes, which has led to reduction in the time spent outside by the children. But in our study, we found that the prevalence is $39.6 \%$. The reduction in prevalence of myopia is due to regional variation and due to the study conducted in rural area.

Czepita et $\mathrm{al}^{12}$ noted that gender influences the occurrence of myopia in school-going children aged 6 to 18 years. Similarly, in our study, $43.44 \%$ were males, while $56.56 \%$ were females with myopia.

A study on myopia among schoolchildren in India was conducted by medical students of Al-Ameen Medical College. In the study conducted from 2003 to 2006 among 549 students ( 279 boys and 270 girls), it was found that prevalence of myopia was $8.6 \%$ among schoolchildren in South India, ${ }^{13}$ whereas in our study it came out to be $39.6 \%$, which is quite high. This could be due to difference in regional variation and due to the study conducted in rural area.

A study on relationship of reading habit and prevalence of myopia was done by Department of Ophthalmology, Quassim University. In this study undertaken from 2000 to 2003 among 320 students aged 7 to 12 years, it was found that those who read book at a distance $>30 \mathrm{~cm}$ for $>30$ minutes in low illumination and in supine position were more prone to develop myopia, which was comparable to our study. Prevalence was found to be $46 \%{ }^{14}$

A study on "Reading, writing, working on computer or watching television and myopia" by the Department of Ophthalmology, Pomeranian Medical University, Poland, among 5,865 school proved that myopia occurs more often in those who read and write $>2$ hours/day, work 0.8 hours/day on computer, and watch TV $>2$ hours/day. ${ }^{15}$ Similarly, in our study, reading books at a distance $>30 \mathrm{~cm}$, continuous reading for 2 to 4 hours, lower levels of outdoor activities, and computer use of 1 to 2 hours had direct relationship in the development of myopia.

A study on prevalence of myopia in children with family history of myopia by the Department of Ophthalmology, Singapore University, found that children with family history of myopia were more prone to myopia. ${ }^{16}$ In our study, there was no significant relationship between these two factors probably due to lack of awareness and illiteracy regarding regular eye checkups, which has led to undiagnosed myopia.

In a study on prevalence of myopia in primary schoolchildren of Qazuin University of Iran by Mohammed Nijad, Shafaq Ali Rahmath, and Mohammed Baraka, prevalence of myopia in schoolchildren was $65.03 \%$. Prevalence of myopia was more in females (60.7\%) and less in males (39.3\%). ${ }^{17}$ But, in our study, the prevalence was found slightly more in males (51.2\%) and less in females $(48.8 \%)$ probably due to male preponderance in rural areas and regional variation.

\section{CONCLUSION}

Due to high magnitude of uncorrected myopia, it appears to be a public health problem both in urban and rural areas, which suggest that an increase in outdoor activity may help to reduce the magnitude of the problem. There is need that national blindness control program should be integrated with the Sarva Shiksha Abhiyan program and there should be mandatory school vision screening at regular interval in all the schools. Large-scale visual acuity screening programs must be launched to detect low vision due to myopia early and an annual checkup to update the spectacle prescriptions. Public and school-based health education programs may also be targeted at a very young age. Schoolteachers should be involved for positive reinforcement of schoolchildren for screening. Also, knowledge regarding ocular hygiene in the form of proper reading distance, distance of watching TV and computer use, illumination while reading, and maintaining correct posture while reading should be inculcated in the children right from preschool.

\section{LIMITATIONS}

The data were based on findings from one school of Wardha city; hence, the results may not be universally reflective, especially due to the known variation reported from urban and rural regions. Additionally, due to limited period of 6 months, the sample size was kept small, which could have reflected underdiagnosed cases of myopia in schoolchildren.

\section{REFERENCES}

1. Resnikoff S, Pascolini D, Mariotti SP, Pokharel GP. Global magnitude of visual impairment caused by uncorrected refractive errors in 2004. Bull World Health Organ 2009 Jan;86(1):63-70.

2. Morgan IG, Ohno-Matsui K, Saw SM. Myopia. Lancet 2012 May;379(9827):1739-1748.

3. Pan CW, Ramamurthy D, Saw SM. Worldwide prevalence and risk factors for myopia. Ophthalmic Physiol Opt 2012 Jan;32(1):3-16. 
4. Vitale S, Sperduto RD, Ferris FL 3rd. Increased prevalence of myopia in the United States between 1971-1972 and 1999-2004. Arch Ophthalmol 2009 Dec;127(12):1632-1639.

5. Dandona R, Dandona L, Srinivas M, Sahare P, Narsaiah S, Muñoz SR, Pokharel GP, Ellwein LB. Refractive error in children in a rural population in India. Invest Ophthalmol Vis Sci 2002 Mar;43(3):615-622.

6. Murthy GV, Gupta SK, Ellwein LB, Muñoz SR, Pokharel GP, Sanga L, Bachani D. Refractive error in children in an urban population in New Delhi. Invest Ophthalmol Vis Sci 2002 Mar;43(3):623-631.

7. Ghosh S, Mukhopadhyay U, Maji D, Bhaduri G. Visual impairment in urban school children of low-income families in Kolkata, India. Indian J Public Health 2012 Apr-Jun;56(2): 163-167.

8. Curtin, BJ. The myopias: basic science and clinical management. Philadelphia, PA: Harper and Row, 1985.

9. Curtin B. Topics to be considered when establishing standards for clinical myopia studies. Acta Ophthalmol (Suppl) 1988 Apr;66(S185):61-62.
10. Angle J, Wissmann DA. The epidemiology of myopia. Am J Epidemiol 1980 Feb;111(2):220-228.

11. Ruben, M.; Khoo, CY. Contact lenses: medical aspects. Singapore: PG Publishers; 1989.

12. Czepita D, Mojsa A, Ustianowska M, Czepita M, Lachowicz E. Role of gender in the occurrence of refractive errors. Ann Acad Med Stetin 2007 Jun;53(2):5-7.

13. Gogate P, Soneji FR, Kharat J, Dulera H, Deshpande M, Gilbert C. Ocular disorders in children with learning disabilities in special education schools of Pune, India. Indian J Ophthalmol 2011 May-Jun;59(3):223-228.

14. Mujad F, Sawad M, Jazir A, Al-Malik H. Oman J Ophthalmol 2011;4(2):57.

15. Ip JM, Saw SM, Rose KA, Morgan IG, Kifley A, Wang JJ, Mitchell P. Euro J Sci Res 2006;28(2):174.

16. Anamaneni S, Bindu H, Reddy KP, Vishnupriya S. Am J Ophthalmol 2005;4(3):213.

17. Mohammed N, Ali Rahmath S, Mohammed B. J Indian Med Assoc 2007;105(4):169. 